\title{
Redefining the Roles of Master and Apprentice: Crossing the Threshold Through the Co-Creation of a First-Year Seminar
}

\author{
*Elizabeth Kiester, PhD, Department of Sociology, Albright College, Reading, USA \\ Joseph Holowko, Department of Computer Science and Political Science, Albright College, \\ Reading, USA
}

Contact: ekiester@albright.edu

\begin{abstract}
Students as Partners is an innovative approach to higher education that seeks to redefine both student and faculty roles and expectations on college campuses through the creation of equitable and inclusive partnerships in a variety of ways. This paper details our research in the co-creation of the curriculum for an undergraduate first-year seminar. It describes our journey from conceptualization to assessment of the course including creating the class, administering it for first-year students in the fall of 2018, and evaluating how successful the course was based on both our own perspectives, as well as student course feedback. Findings suggest that both partners had a transformative experience in which they crossed a threshold, creating new expectations surrounding roles and relationships for future student-faculty partnerships. Additionally, the students enrolled in the course provided feedback about the perceived successfulness of the co-created curriculum and the overall course experience based on our collaborative efforts.
\end{abstract}

\section{KEYWORDS}

students as partners, curriculum development, first-year seminar, co-creation

When it comes to higher education, we find ourselves constantly innovating pedagogies to reach a population that changes substantially faster than the institutions themselves. Many educators seek ways in which to better approach increasingly diverse students in inclusive and equitable ways. To do so, we must break down institutional hierarchies and barriers when it comes to the traditional faculty-student relationship. Students as Partners (SaP) is an innovative approach to higher education that "aims to capture an aspiration for working together in higher education in a way that rejects traditional hierarchies and assumptions about expertise and responsibility" (Cook-Sather, Matthews, Ntem, \& Leathwick, 2018, p. 1). While traditional subject-based research partnerships between faculty and students have long existed in higher 
education, this pedagogical approach seeks to acknowledge student expertise and shift more power to them in a wide array of decision-making processes across campuses.

This paper details our experience with the co-creation of the curriculum for an undergraduate first-year seminar (FYS) course. We are an assistant professor of sociology and a student partner majoring in computer science and political science. It describes our journey from conceptualization to assessment of the course including creating the class, administering it for first-year students in the fall of 2018, and evaluating the success of the course based on both our own perspectives as well as student course feedback. We found that the marriage of institutional expectations for an FYS and the SaP pedagogy made perfect sense. FYS classes are typically designed to focus on student success and retention of first-year students. Based on existing research, partnering with a current student in the curriculum design could enhance and reinforce these goals by relying on their expertise as a student rather than faculty's assumptions about what incoming students need.

We begin our discussion with a review of the SaP literature. We rely on Cook-Sather's (2014) conceptualization of the threshold concept to frame our own personal threshold moments during this project. We also highlight the SaP pedagogical fit for an FYS course. Next, we present three perspectives on the project: that of the faculty partner, the student partner, and of the entire class compiled from themes found in enrolled student feedback. Findings suggest that SaP allows for a unique type of innovation when a faculty member and student collaborate on curriculum design. This is especially true in the context of an FYS course. However, the student partner experienced some negative costs associated with his role in the course. Lastly, while both partners each had a transformative experience in which they crossed a threshold of new institutional roles and expectations for future student-faculty relationships, students in the course also reaped some of the benefit of this new type of partnership. In fact, it was the student partner's presence in the course that created a sense of belonging for firstyear students struggling to find their sense of place on a college campus.

\section{LITERATURE REVIEW}

Cook-Sather, Bovill, and Felten (2014) focus on reciprocity, respect, and responsibility as the core principles that should guide student-faculty partnerships. While subject-based student-faculty partnerships have the longest history in higher education, SaP as a pedagogy suggests that these traditional relationships are not inherently equal when it comes to power in the partnership as the faculty mentor typically takes the lead while the student acts as an apprentice. Yet these partnerships also provide evidence that students often thrive in their college experience when they develop these close working relationships with faculty. Additional research has focused on students as consultants in partnership with a faculty member (CookSather, 2014; Cook-Sather \& Motz-Storey, 2016; Gourlay \& Korpan, 2018; Kandiko Howson \& Weller, 2016) along with students as mentors to new faculty during the orientation process (Cook-Sather, 2016). However, the most overlooked dimension of SaP is in curriculum design (Loveland, Moys, Tollett, \& Towriss, 2016; Moys, 2018; Moys, Collier, \& Joyce, 2018). Much of the research in this area has also been limited to the context of the United Kingdom. This paper seeks to fill this gap in the literature with our U.S.-based curriculum-design application of SaP. 
Additionally, we are unaware of any literature that focuses on the FYS course context as a model for implementing SaP.

It is important to understand SaP as an ongoing process rather than a static project. Meyer and Land (2006) describe threshold concepts as gateways that lead to transformed understanding. In teaching and learning, one key threshold concept involves transforming the assumption that teachers hold the knowledge that students come to passively learn As a pedagogical approach, SaP embraces this type of threshold moment as a transformative and long-lasting process that changes our way of thinking and redefines relationships across campus, all while encouraging diversity and inclusion of thought (Cook-Sather, 2014; Healey, Flint, \& Harrington, 2014; Matthews, 2017). SaP is about changing relationships permanently rather than just for the duration of the project. The outcomes of this change in process are particularly difficult but highly important for minority students who have not traditionally held positions of power on college campuses (Cook-Sather \& Luz, 2015). In fact, the SaP pedagogy may help students struggling to feel like they even belong on a college campus develop a sense of identity and place in higher education. Student partners take on an authoritative role as subject experts while students in the classroom can see themselves in the student instructor. Developing both a sense of self as a college student and feeling a sense of belonging early can also aid in overall student success and retention outcomes.

The effects of crossing the type of faculty-student power threshold described above can also have affective outcomes on a personal level and disrupt the compartmentalization of institutional life (Cates, Madigan, \& Reitenauer, 2018). Felten (2017) notes that these affective outcomes are due to the emotions that are inherent in interpersonal relationships. Being open to the emotional connections made in a student-faculty partnership is what helps participants cross the threshold in a meaningful and long-lasting way. Most importantly, "the benefit of student involvement in the enhancement of teaching is dependent on the perceived authenticity of student voice within a circumscribed idea of student expertise" (Kandiko Howson \& Weller, 2016, p. 10). SaP can only be successful if all participants are equally invested in the idea that students can be equal contributors to a project because of their own unique expertise. This may seem counterintuitive to many faculty members, who are trained to guard their knowledge, authority, and power carefully. Opening up to a student emotionally to build a relationship while acknowledging the agency and capacity of the student as more than just a passive learner is necessary for crossing the threshold.

Faculty are often the unchallenged authority on a college campus while students sit in the classroom as passive learners. The expertise students bring with them to the classroom often goes overlooked as professors seek to impart the knowledge of their disciplines, as it will appear on final exams. However, SaP seeks to redefine the relationships traditionally found in higher education by breaking down the assumption that knowledge is a one-way street (CookSather \& Luz, 2015; Cook-Sather et al., 2018; Mercer-Mapstone et al., 2017; Peters \& Mathias, 2018). This is especially relevant in an FYS course in which first-year students are learning about the expectations and practices of their institution. Peer instruction, in which the student partner is a subject expert, is particularly meaningful in this context for both the student partner and the student peers they interact with. 


\section{METHODS}

This research was conducted at a small liberal arts institution with a student body of approximately 1,700 students in the Mid-Atlantic region of the United States between June 2018 and January 2019. Our team was comprised of an assistant professor of sociology in her fifth year of teaching at the institution and a computer science and political science double major transitioning from his freshman to sophomore year at the college. This partnership was brought together by a passion for Star Wars and an interest in both teaching and collaborative research. The project was made possible by an internal grant that traditionally facilitates SaP in subject-based faculty-student research partnerships.

Between June and August of 2018, we worked to design an FYS from the ground up, guided by the SaP pedagogy, called "Star Wars: The Good, The Bad, and The Sociology." This course spent half the time teaching first-year students how to be successful in college and half the time practicing critical reading and writing skills using the Star Wars saga and supplemental readings pertaining to introductory sociological concepts. We worked together to select readings and video content, design assignments, create in-class activities, and even build quizzes and exams. Joe helped designate which type of institutional resources should be included on the syllabus and the order in which they should be addressed based on his own first-year experience. Elizabeth made arrangements with these resources for key staff in each area to present their resource to the class. Lastly, we also wanted to include the students in their own SaP project, so we created a semester-long assignment that would culminate in a presentation at a campus-wide venue. The students took on the role of subject-experts and presented course material to over 100 of their peers from all across campus.

From August to December of 2018, the course had 16 students enrolled. It was a racially diverse group of first-year students and included 13 males and three females. We created assessment mechanisms over the summer which were administered to students and collected for analysis upon completion of the course. These tools included feedback surveys administered at both midterm and end of semester along with an extra-credit evaluative question on the final exam specifically asking, "In what ways do you think that being in a co-created course affected your experience in this class? How did your learning experience compare to other courses this fall?" Surveys were administered using Microsoft Forms, and students received extra credit for completion. All open-ended data were coded by both the student and faculty partner for interrater reliability. Following the work of Berg (2009), we practiced open coding, asking ourselves the question, "How did our partnership affect students in the course we designed?" Common themes were then used to develop coding frames, which included the visible presence of the student partner throughout the course, the relatability of having a student partner create the course, and students feeling prepared for their college education as discussed below.

In addition to the feedback data collected from enrolled students, we also relied on our own personal experiences in assessing the usefulness of the SaP pedagogy. We find these subjective disclosures an important part of understanding both our findings and the research that was conducted (Berg, 2009). We each discussed how we came to be interested in the project, the role we played in the partnership when it came to curriculum design, and a reflection on how we each experienced a transformative threshold crossing during our 
partnership. These perspectives are critical in helping other students, faculty, and institutions understand the intricacies of implementing a new pedagogical approach that complements our project findings.

\section{CROSSING THE THRESHOLD}

\section{The faculty partner}

After agreeing to teach a first-year seminar for my institution, I quickly realized I didn't know anything about being a student in today's world. Therefore, I recruited a student partner. I simply asked for a student who had successfully completed their FYS and who loved Star Wars. I am a sociology professor, and he was a rising sophomore in the Computer Science department; this was an interdisciplinary twist that added to the excitement of our partnership.

We began our course-design project by looking for appropriate readings not only on the Star Wars saga and sociology but also on how to be a successful student in college, the importance of higher education, and the value of the liberal arts. Joe helped scour through stacks of books and articles that I had started to collect in the spring. I would give him micro lessons in core sociological concepts including race and gender while also discussing the social institutions of politics, religion, and family, all themes found throughout the films that we hoped to include. He would then determine which readings he felt were accessible and interesting to first-year students. Together we would discuss the rigor and appropriateness of his suggestions. He helped determine how many class periods we might need to cover a certain subject while also preserving space for a breadth of topics. As a non-sociology major, he also made sure that I was providing sociological explanations that were basic enough for non-majors with no prior knowledge of the subject.

Joe was also integral in designing engaging activities. For example, we developed the idea of doing a scavenger hunt around campus. He helped identify the most important resources first-year students would need and should know how to locate. He then developed a passport for students to have stamped at each location. These passports also included a helpful fact Joe developed regarding each location. We then used this list to schedule additional fieldtrips to each location for further instruction. It was invaluable to have my student partner's help in these projects because he had recent first-hand experience with these services and the order in which students would likely need to access them.

Other ways we collaborated included in-class activity design and writing assignments. Joe was able to articulate what made an assignment accessible and interesting to him during his first year of college. He provided a perspective unique from my own and helped me establish a reasonable level of rigor. An example were reminders from him as to the workload and expectations students would also be facing in their ENG101/102 course and how our class should complement those assignments. When it came to developing grading rubrics for our assignments, Joe helped me understand how to best make sure feedback would be received constructively rather than critically. He also helped design a scaffolded series of grades in which assignments started out low stakes and became increasingly larger portions of the course grade. He emphasized that this would help students feel less deflated and hopeless at the beginning of their college career and incentivize them to respond positively to feedback. Lastly, 
in order to ensure his presence in the course when it was offered in the fall, Joe filmed a series of short videos that were integrated into the class, explaining the course, the assignments, and "tips and tricks" for being successful throughout the class. ${ }^{1}$ These would prove to be extremely successful at demonstrating Joe's presence in the class, even when he was not physically present.

Initially, I found this project to be very unsettling. This partnership demanded that I essentially pre-test all my ideas with a student, something I don't think many faculty think about or do when we plan a new course. We run it the first time, often creating on the fly, and then we make adjustments based on how it went. Giving up this kind of control to an untrained undergraduate student went against all my training, especially as a female academic needing to possess an air of authority for her students to take her as seriously as their male professors. But then it became freeing. I realized I was still a part of the partnership and could help make sure the course met a specific level of rigor and included all institutional requirements. I spent less time worrying about reaching the students in my class, and I put more effort into helping Joe turn his ideas into praxis. I taught him about sociological concepts, and he helped make them accessible to incoming first-year students, most of whom were not sociology majors. He taught me about computer software capabilities and ways of including technology in the classroom. His enthusiasm for Star Wars, especially the newer films and TV series, was infectious. I explained to him my fondness for the classic trilogy, and he discovered the importance of context when viewing a cultural artifact. Most importantly, he relied on his own FYS experience to shape the experiences of the next incoming class. And I have never felt more prepared to teach a class in my entire career.

I was then able to take this transformed sense of partnership into the classroom. I did it by showing Joe's videos in class as well as posting them on our institution's learning management system; Moodle. I continuously opened myself up to critique by students in the class both informally and through the assessment mechanisms designed with Joe. We also had the students create a student-led, campus-wide presentation, empowering them to teach the campus about their semester-long projects. This was another example of how Joe and I sought to teach the campus about SaP both inside and outside the classroom. Attendees were exposed to an explanation of my partnership with Joe while also seeing first-year students taking command of course material. Students enrolled in the course became empowered with their newfound expertise and agency, and many cited the event as their favorite part of the course in their feedback.

In The Empire Strikes Back (Kurtz \& Kersher, 1980), Yoda tries to teach Luke a lesson after his plane sinks even further into the Dagobah swamps. Luke is convinced that he will never be able to get it out. "Always with you it cannot be done. . . Y You must unlearn what you have learned." In embarking on a SaP endeavor, I too had to unlearn what I had learned about traditional student-faculty relationships, expertise, and institutional role expectations. Once I did, I crossed the threshold.

\section{The student partner}

As a student, I have always been interested in the idea of pursuing research in college. At my current institution, I was fortunate enough to receive internal funding to pursue this 
interest. I knew I wanted to do research during my undergraduate years; I just did not know how I would come across it or what I would be studying. In the fall semester of my first year of college, I came across an advertisement from Dr. Kiester detailing a possible student-faculty research opportunity. After seeing this advertisement recruiting students interested in Star Wars and FYS, I knew it was the perfect opportunity for me. After going through Dr. Kiester's application process, I was fortunate to be selected as the student partner. We applied for the available internal funding and became research partners in the summer of 2018, ready to pursue SaP.

Over the summer, I spent a significant amount of time learning the processes and thoughts of a professor in higher education designing a new course. Being only a year out of high school at the time, I had my own ideas as to how professors thought and how classes were developed, but nothing close to what I learned with this experience. This was a very interesting project because essentially, I was learning the "behind the scenes" of college. I had the opportunity to talk to a professor outside my own coursework, learning about everything that goes into curriculum development. This was all on top of being equally responsible for an entire FYS course for the upcoming fall semester.

It was not just being a student and a professor that made this research partnership interesting, but also the fact that it was interdisciplinary as we are a team made up of a sociology professor and a student studying computer science and political science. Throughout the summer, I realized that it was not just me who was learning new things. I was teaching Dr. Kiester about how it is to be a student at the institution. I was also able to show my own academic strengths while contributing to the course and our work together with my computer science background by providing technical skills she lacked and making our work more efficient and accessible to students in the class.

During this double-sided learning experience, we came across an article detailing a particularly resonating concept in SaP work: the threshold concept. We found ourselves experiencing this exact concept, crossing the threshold between student and faculty roles through collaboration on this course-design project. I crossed the threshold utilizing this research and, with the help of Dr. Kiester and the course we made, provided a similar opportunity for other students to also have a transformative experience.

Once the class was in session, it was a very abnormal experience to be a student who just happened to also be an "instructor" to a handful of my peers coming into the college. It was both a rewarding experience and an unsettling one. It was rewarding in that I was able to be a mentor to some incoming first-year students and assist them in their academic journey by giving simple tips to aid their studies. I was also able to provide inspiration to a few of the students participating in the course by sparking a desire to venture into their own SaP work in the future.

However, it was not all good feelings that came from being the quasi-instructor that I was to these students. I felt as if there was a certain pressure to be a model student for them, as I was the one who helped design and implement assignments that they would be graded on. This affected my day-to-day academics for my own scholarly experience as I held myself to a higher standard when in communication with the students taking the course. This was a positive motivator for me to better myself, but it also added an abnormality to my semester. I 
also noticed different changes in tone throughout the semester from various participating students towards me, because their viewpoints shifted from that of a peer to that of a stereotypical student and instructor. This is also another thing that I did not think to consider when working in a SaP mindset: the social implications that come from being a peer who was partially responsible for what they would be graded on.

These social implications are often overlooked in the SaP literature, which is typically very scientific and lacks the emotional responses of the student participants. In my experience, taking up the work as an instructor makes for a vastly different college experience. In being an instructor who is also a peer, there is no longer the barrier of instructor-to-student; all communications are student-to-student, which makes for a much more rewarding and complicated experience for different interactions. Some rewarding moments for me included students showing a desire to achieve their goals at college and being positively affected by participating in our SaP experience. These were some of the best feelings from the whole experience, because they were what I aimed to do in this research project. I wanted to provide a successful entrance into higher education, in which I created a course that could teach the basics of college and inspire the students involved to act on their passions and get the most out of their time in college. When asked about their experience in the class, one student responded:

Since this class was co-created under a student-faculty partnership, it has definitely affected my experience in the class. Having a student only a year older help create a class made the class based on a student's perspective. Therefore, him being a student, he knew how much a student can handle and what wasn't important. It affected my experience because I realized if another student can get through this class then so can I. My learning experience in this class taught me how to write better papers and work harder towards my goals. It taught me to look at things from a different perspective than I am used to. This will not only help me in my other courses, but in real life.

Receiving responses like this allowed me to see the positive influence that a successfully cocreated course could have on incoming first-year students.

However, there were also negative interactions that included direct personal criticisms from students and a forced social separation. For example, when talking with some students before tests, they would sometimes ask for information I would not give them, so I would have to withdraw from the conversation. Other instances included hearing occasional negative comments about having a peer in the role of instructor. Students react differently in a course and in response to their professors. Based on my observations, these reactions appear to be amplified, both positively and negatively, when the course design and instruction comes not only from a professor but also from a peer.

Having spent some time unofficially working as a teaching assistant (TA) for another professor, I can also say that this experience differs from this more traditional student-asinstructor relationship. As a TA, my role had more to do with helping fellow students master subject material with an understanding that I was not privy to all course content. However, in this instance, students were well aware that I had helped develop content including questions 
for quizzes and exams. It was this knowledge that created a negative reaction from peers when I refused to simply give them access to the content and the answers.

Overall, I hope that this research helps break down the stereotypical barrier between students and professors and ends the social implications for students participating in this innovative work for higher education. I believe that if SaP becomes more prevalent in academia, then it will foster a more creative and collaborative approach to the college experience. I am happy to have had this opportunity to work as a student partner on such an innovative pedagogical approach, and I am thrilled to be a part of the SaP pilot program at my institution. I am going to continue to work on breaking the barriers between myself as a student with my other professors in the future, and take more control over my own education as well as the people around me. This is all due to crossing the threshold.

\section{The class}

Sixteen first-year students took this class during their first semester at the institution. The class was designed to help first-year students develop basic college skills including critical thinking, writing, and oral communication. Students were also tasked with participating in a SaP project of their own. They had to create presentations that were the culmination of a semesterlong assignment and that required group work to complete. At the end of the semester, each group then made a campus-wide presentation, demonstrating the way in which they had become subject experts.

Throughout the class, there were various feedback mechanisms given to the students to gauge the success of the course. This included both a midterm and end-of-semester survey evaluating satisfaction with the course along with whether or not the student partner's impact on the course felt noticeable (e.g., Do you think Joe's input in designing this course has been noticeable?; How satisfied are you with the writing assignments in this course?). Additionally, we looked at institutionally administered course evaluations for any mention of level of satisfaction with the course or the student partner's impact. After compiling the data and going through the open coding process, we noticed some key themes in students' feedback. These themes included the visible presence of the student partner throughout the course, the relatability of having a student partner create the course, and students feeling prepared for their college education.

The first theme of the student feedback pertained to the visible presence of the student partner throughout the course. This was accomplished with pre-recorded video segments by Joe directly speaking to the class. We decided to use these videos to make sure that students were invested in SaP and knew that Joe was an integral part of the course design and implementation even though he was enrolled in his own courses at the time this course was offered. Students responded positively to his presence:

Being able to walk into class and seeing a video of Joe explaining the next assignment and his suggestion of when to start it. Also, being able to have a student to talk to when you have any questions was really awesome too. My learning experience was completely different compared to my other courses. Having a student and a professor made me learn so much more and I was truly appreciative to have this opportunity. 
I believe that the co-created class under a student-faculty partnership was more beneficial. This affected my experience by giving a better understanding to the class. This was done with videos from Joe at the beginning of every chapter. Also, by a clear explanation on what kind of effort was required to do well.

I feel that this class being co-created in partnership with a student definitely aided in the explanation of the sociological aspect of the class. The terms were clear and understandable for a first-year class that consisted of many different majors and levels of interest in sociology.

Students often smiled when Elizabeth would play a new video at the beginning of class, often saying "Hi Joe" in response to the video. While faculty often convey to their classes things such as course expectations, assignment details and deadlines, and substantive material, hearing the same information come from a peer was perceived to be more beneficial than coming from the professor.

Second, not only was Joe's presence noticeable and welcome, students reported that he made the class more personable. Using SaP in an FYS provides students with a more relatable pillar in their education. Students noted in their feedback that faculty have not been in the seat of an undergraduate student for a very long time, making them feel less approachable. However, under the SaP approach, students appreciated that they had a peer providing professorial insight alongside the faculty member, giving students someone more relatable in the course. When asked about their experience in the class, this was the most prevalent theme, as the following student comments demonstrate:

My experience in this class felt very familiar and welcoming meaning that Joe knows what being a student is like, so he co-created the course with that in mind. Making it simple.

It honestly made the class better. Joe's input made it better for the students. His input helped us a lot because he knows what it's like being a college student. He was able to help set things up so that we didn't become overwhelmed. This course was probably one of my favorites because I like Star Wars and I like Sociology. It was able to blend the two. This course was very interesting.

I think this affected me in a good way. Joe sits in my seat everyday and understands what it's like to be a student in today's time.

It affected my experience by giving me something to relate to within the class. I knew that it wasn't going to just be $100 \%$ all the professor's input going into the course. My learning experience was much greater when compared to other courses because I had many different ways to learn. 
I feel like it affected my experience because you got to feel the student part of the class and also because I know Joe. I got help from him and got to ask him questions about the class.

While we had anticipated that there would be benefits for both the student and faculty partners when utilizing SaP to cross the threshold, we did not anticipate the significant impact it appears to have had on the students in our co-created class. They too seem to have crossed a threshold when it comes to their assessment of having someone deemed more relatable conveying the same information. This increased their perceptions of success in the class and helped them develop a sense of belonging on campus.

The third theme that we noticed in the student feedback was the level of preparedness students felt they achieved in this course. Since student success is a primary goal of an FYS course, we designed a variety of assessments that would measure this goal including writing assignments, tests, group work, and public speaking presentations. Students suggested in their feedback that the course did make them feel adequately prepared to handle the rigor of future college courses:

This was a class that assigned a lot of work, between papers and other work, just like my English class. In my English class, not many people understood what was due and when. However, in this class the structure was made so everyone could understand.

I had to do more intense group work for this course than any other course that I am taking, which for me took away from how I completed assignments that were part of the entire group "effort."

My least favorite part of the Experience Event was the nerves I had before it. I get really nervous and I was super scared to present in-front of many people. My favorite part of it was me overcoming my nerves and being proud of myself after it.

These responses suggest that Joe's collaboration in the curriculum design resonated with his peers. His understanding of what skills students needed to build in their first semester of college and how to get them to actively engage with our course assignments was invaluable to our FYS.

Constant feedback is important for any course creator, but even more so for ones seeking to actively give students an amplified voice in their own education. It gives an idea of what students like and dislike about a course. This feedback is truly irreplaceable in the assessment of the success of a course, particularly one grounded in SaP. We were grateful not only for the positive feedback but also for more critical assessments of assignments or course structure that could be used to improve the course in its next iteration, such as the following comments:

This course was one of my favorite courses this semester. ... Knowing that this class was co-created with a student, and was also being taught for the first time, I came into 
the class expecting for there to be rough spots. Things like the essays at the beginning of the semester or the scheduling of out of class trips felt off. However, they were off by product of it being a new class, not a failure on behalf of the curriculum. My all-time favorite part about this class was the Experience Event we did, something none of my other classes would have even thought of doing. Projects like that showed genuine collaboration by both student and teacher, and I'd love to see more in the future.

I do not know how to incorporate it into a sociology class, but I would recommend talking about the music of Star Wars for a day. The soundtrack is just as memorable and well-known as the characters, along with the fact that John Williams did an amazing job in every movie. It would be interesting to talk about how themes are reused in different trilogies, and also how different songs are used in different contexts throughout a trilogy such as "Duel of Fates" in the prequels.

We loved this last comment so much, we decided to create a Sociology of Star Wars music module for the class in the fall of 2019. The students seemed to appreciate this course overall and provided a large amount of feedback and their personal assessments of the course throughout its duration. We feel this is imperative to both an FYS course and the SaP model, and our use of it in curriculum development made a positive learning experience for both the enrolled students as well as ourselves.

\section{DISCUSSION AND CONCLUSION}

Over the past six months, we have actively sought to change the student-faculty dynamic while increasing the success of an FYS course at our institution. We embarked on this project excited to create a new experience for ourselves and our students. In doing so, we discovered several implications of SaP pedagogy, particularly in the FYS course context.

First, we found that the FYS context greatly benefits from the innovation of the SaP pedagogy. Students felt more engaged and connected to the course because of the student partner's role in the course design. His presence in the class, even in the form of a pre-recorded video, gave them confidence and helped them feel as though they were more prepared to face the challenges of college life and that they in fact belonged on a college campus. This is particularly important for first-year students and especially meaningful for first-generation students who least know what to expect in college. These findings also have implications when it comes to the issue of stereotype threat that many contemporary students face when they arrive on a college campus. Steele (1997) suggests that stereotype threat is a sense of not belonging coupled with a fear of performing a negative stereotype associated with one's group identity characteristics. This is especially relevant for racial minorities and first-generation college students with no idea what to expect on campus or in the classroom. The findings from our racially diverse sample suggest that SaP may have a role in helping students overcome this threat by providing them a sense of belonging and giving them a boost in confidence that they will be successful in college. These results would also have implications for student retention which is particularly important during the fall to spring semester of a first-year student. 
Secondly, our findings demonstrate how impactful a peer can be when given the chance to be a subject expert. Historically, we have seen this in traditional student leader roles on campuses including resident assistants, peer tutors, and student government. Our findings indicate that peers in curriculum design and their presence in the classroom should also be utilized to increase student success and connectedness, especially when it comes to incoming first-year students. As our students noted from their own SaP experience, they were very proud of their participation in the campus wide presentation event which made not only them, but students in the audience, imagine what their own student-faculty partnership might look like and in what other areas they might be viewed as subject experts. SaP is then capable of increasing student investment in the college experience in general and in their campus in particular.

Finally, both partners had a transformative experience in which they crossed the threshold of traditional faculty-student relationships. We concur that "genuine partnership in learning and teaching is an act of resistance to the traditional, often implicit, but accepted, hierarchical structure where staff have power over students" (Matthews, 2017, p. 6). Both partners felt an equal opportunity to contribute to the course design, each having to learn to cope with a shift in authority. Elizabeth had to break free from authoritative expectations as a subject expert to allow Joe the freedom to teach her what students want and need. Joe had to overcome submissive expectations as a passive learner seeking knowledge to assert his expertise at being a successful student. While this originally made us both uncomfortable, the experience changed our outdated view of traditional relationships on a college campus and made us want to advocate for reimagining a larger role for student-faculty partnerships in classrooms across campus, not only for the student and faculty partners but for the students enrolled in their class.

Through our own perspectives about crossing the threshold combined with student feedback on the course's success, it appears that relying on the expertise of the student partner was successful in changing the experience of each person touched by this course. Students enrolled in the class and those who attended the student-led campus event approached us for advice about initiating their own SaP curriculum-design project at the institution. It is this enthusiasm and feedback that we hope to share across our own campus while also inspiring and encouraging our readers to seek SaP opportunities at their own institutions without waiting for a campus-wide initiative. By sharing our own subjective experiences as the researchers, we hope to strengthen the understanding of the transformative threshold moment and its significance in perpetuating SaP as a process rather than a static moment. This is important when considering the long-lasting implications for the student success and retention campuses seek.

This project clearly has institutional and geographic limitations that we note. Additionally, Bindra et al. (2018) note a significant problem with SaP pedagogy in that it can act as a mechanism that reproduces inequality at institutions that fail to acknowledge the importance of including minority students even if they do not meet certain GPA or academic standards. They note that SaP projects that do not adequately compensate student partners monetarily also privilege wealthy students who can afford to partake in the experience without 
pay. Disrupting these traditional power structures is a valuable component of SaP as a threshold concept and should be further investigated.

This research was successfully reviewed according to our institution's IRB committee guidelines.

\section{ACKNOWLEDGEMENTS}

We would like to thank the Albright Creative Research Experience committee for funding this project. We would also like to thank the anonymous reviewers for their valuable feedback in strengthening our paper. Finally, we would like to thank our institution's administration for allowing us to pilot this new pedagogy on our campus.

\section{NOTES}

1. The student partner recorded eight videos played in class which were also integrated in the LMS. They ranged from 1-3 minutes in length and included a welcome to the class, writing tips and tricks, writing assignment instructions, midterm exam study hints, previews of upcoming course materials, presentation help, how to be successful on the final exam, and a goodbye. They would appear about every other week as the class was learning a new skill or making a transition in subject material.

\section{NOTE ON CONTRIBUTORS}

Elizabeth Kiester is an Assistant Professor of Sociology at Albright College where she teaches core sociological courses, family studies courses, and an FYS on the Sociology of Star Wars.

Joseph Holowko is a third-year undergraduate student at Albright College where he is studying computer science and political science.

\section{REFERENCES}

Berg, B. L. (2009). Qualitative research methods for the social sciences. Boston: Allyn \& Bacon.

Bindra, G., Easwaran, K., Firasta, L., Hirsch, M., Kapoor, A., Sosnowski, A., Stec-Marksman, T., \& Vatansever, G. (2018). Increasing representation and equity in students as partners initiatives. International Journal for Students as Partners, 2(2), 10-15. https://doi.org/10.15173/ijsap.v2i2.3536

Cates, R. M., Madigan, M. R. \& Reitenauer, V. L. (2018). "Locations of possibility": Critical perspective on partnership. International Journal for Students as Partners, 2(1), 35-46. https://doi.org/10.15173/ijsap.v2i1.3341

Cook-Sather, A. (2014). Student-faculty partnership in explorations of pedagogical practice: A threshold concept in academic development. International Journal for Academic Development, 19(3), 186-98. https://doi.org/10.1080/1360144X.2013.805694 
Cook-Sather, A. (2016). Undergraduate students as partners in new faculty orientation and academic development. International Journal for Academic Development, 21(2), 151-62. https://doi.org/10.1080/1360144X.2016.1156543

Cook-Sather, A., Bovill, C., \& Felten, P. (2014). Engaging students as partners in learning and teaching. San Francisco, CA: John Wiley \& Sons, Inc.

Cook-Sather, A. \& Luz, A. (2015). Greater engagement in and responsibility for learning: What happens when students cross the threshold of student-faculty partnership. Higher Education Research \& Development, 34(6), 1097-109. https://doi.org/10.1080/07294360.2014.911263

Cook-Sather, A., Matthews, K. E., Ntem, A., \& Leathwick, S. (2018). What we talk about when we talk about students as partners. International Journal for Students as Partners, 2(2), 1-9. https://doi.org/10.15173/ijsap.v2i2.3790

Cook-Sather, A., \& Motz-Storey, D. (2016). Viewing teaching and learning from a new angle: Student consultants' perspectives on classroom practice." College Teaching, 64(4), 16877. https://doi.org/10.1080/87567555.2015.1126802

Felten, P. (2017). Emotion and partnerships. International Journal for Students as Partners, 1(2), 1-5. https://doi.org/10.15173/ijsap.v1i2.3070

Gourlay, G., \& Korpan, C. (2018). Genuine students as partners: How a teaching assistant consultant program put students as partners into practice. International Journal for Students as Partners, 2(2), 106-14. https://doi.org/10.15173/ijsap.v2i2.3567

Healey, M., Flint, A., \& Harrington, K. (2014). Engagement through partnership: Students as partners in learning and teaching in higher education. York: Higher Education Academy.

Kandiko Howson, C., \& Weller, S. (2016). Defining pedagogic expertise: Students and new lectures as co-developers in learning and teaching. Teaching and Learning Inquiry, 4(2), 1-14 https://doi.org/10.20343/teachlearninqu.4.2.6.

Kurtz, G. (Producer) \& Kershner, I. (Director). (1980). Star wars: The empire strikes back [Motion picture]. United States: Lucasfilm.

Loveland, P., Moys, J.-L., Tollette, H., \& Towriss, M. (2016). Typo-Resouce: Developing T\&L support materials through collaboration. The Journal of Educational Innovation, Partnership, and Change, 2(1).

Matthews, K.E. (2017). Five propositions for genuine students as partners practice. International Journal for Students as Partners, 1(2), 1-9. https://doi.org/10.15173/ijsap.v1i2.3315

Mercer-Mapstone, L., Lucie Dvorkova, S., Matthews, K.E., Abbot, S., Cheng, B., Knorr, K., Marquis, E., Shammas, R., \& Swaim, K. (2017). A systematic literature review of students as partners in higher education. International Journal for Students as Partners, 1(1). https://doi.org/10.15173/ijsap.v1i1.3119

Meyer, J. H. F., \& Land, R. (2006). Overcoming barriers to student understanding. London: Routledge.

Moys, J.-L. (2018). Promoting diversity through developing a sense of community. International Journal for Students as Partners, 2(2), 135-43. https://doi.org/10.15173/ijsap.v2i2.3547

Kiester, E. \& Holowko, J. (2020). Redefining the roles of master and apprentice: Crossing the 80 
Moys, J.-L., Collier, J., \& Joyce, D. (2018). By design: Engaging graphic communication students in curriculum development. The Journal of Educational Innovation, Partnership, and Change, 4(1).

Peters, J., \& Mathias, L. (2018). Enacting student partnership as though we really mean it: Some Freirean principles for a pedagogy of partnership. International Journal for Students as Partners, 2(2), 53-70. https://doi.org/10.15173/ijsap.v2i2.3509

Steele, C. (1997). A threat in the air: How stereotypes shape intellectual identity and performance. American Psychologist, 52(6), 613-29. https://doi.org/10.1037//0003066x.52.6.613 